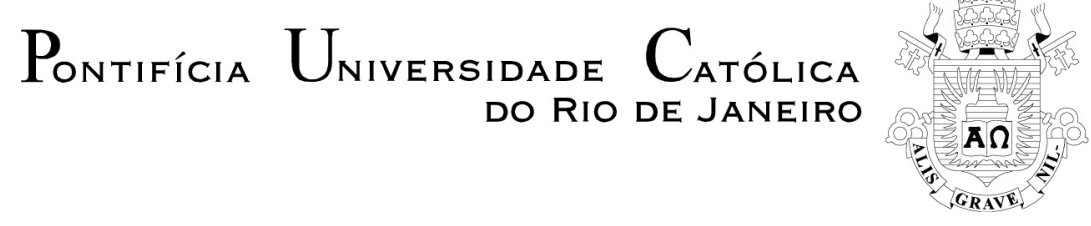

Carlos Eduardo Klimick Pereira

(klimick@historias.interativas.nom.br)

\title{
UMA PONTE PELA ESCRITA \\ A narratividade do RPG como estímulo à escrita e à leitura
}

Tese de Doutorado

Tese apresentada ao Programa de Pós-graduação em Letras da PUC-Rio como requisito parcial para a obtenção do título de Doutor em Letras

Orientadora: Eliana Lúcia Madureira Yunes Garcia

Rio de Janeiro, Abril de 2008 


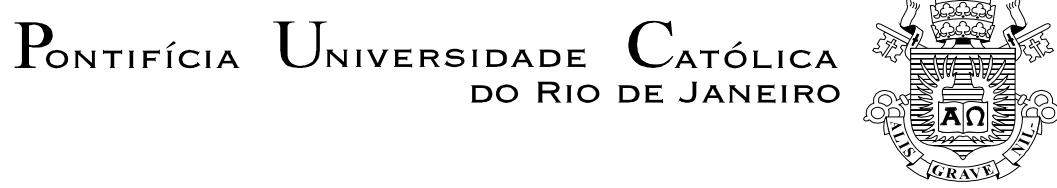

CARLOS EDUARDO KLIMICK PEREIRA

\section{UMA PONTE PELA ESCRITA}

Tese apresentada como requisito parcial para obtenção do grau de Doutor pelo programa de Pós-Graduação em Letras do Departamento de Letras do Centro de Teologia e Ciências Humanas da PUC-Rio. Aprovada pela Comissão Examinadora abaixo assinada.

Profa. Eliana Lúcia Madureira Yunes Garcia

Orientadora

Departamento de Letras - PUC-Rio

Profa. Pina Maria Arnoldi Coco

Departamento de Letras - PUC-Rio

Prof. Érico Braga Barbosa Lima

PUC-Rio

Profa. Andréa Cristina Pavão Bayma

Instituto Superior de Educação do Rio de Janeiro

Prof. Lucelena Ferreira Fourneau

UNESA

Prof. Paulo Fernando Carneiro de Andrade

Coordenador Setorial do Centro de Teologia

e Ciências Humanas - PUC-Rio

Rio de Janeiro, de de 
Todos os direitos reservados. É proibida a reprodução total ou parcial do trabalho sem autorização da universidade, da autora e do orientador.

\section{Carlos Eduardo Klimick Pereira}

Doutorado em Literatura Brasileira, com pesquisa na Formação do Leitor, e mestrado em Design pela Pontifícia Universidade Católica do Rio de Janeiro (2003). Tem experiência na área de Educação, com ênfase em Tecnologia Educacional, atuando principalmente nos seguintes temas: roleplaying game, educação, interatividade, formação do leitor, design e roteirização didáticos, histórias interativas.

Ficha Catalográfica

Pereira, Carlos Eduardo Klimick

Uma ponte pela escrita: a narratividade do RPG como estímulo à escrita e à leitura / Carlos Eduardo Klimick Pereira ; orientadora: Eliana Lúcia Madureira Yunes Garcia. - 2008. 200 f. : il. ; $30 \mathrm{~cm}$

Tese (Doutorado em Letras)-Pontifícia Universidade Católica do Rio de Janeiro, Rio de Janeiro, 2008.

Inclui bibliografia

1. Letras - Teses. 2. Leitura. 3. Escrita. 4. Complexidade. 5. Barthes. 6. Narrativa. 7. Interatividade. 8. RPG. I. Garcia, Eliana Lúcia Madureira Yunes. II. Pontifícia Universidade Católica do Rio de Janeiro. Departamento de Letras. III. Título.

CDD: 800 
Esta tese é dedicada às duas mulheres da minha vida, minha esposa Eliane, para quem almejo ser um bom companheiro e amante, minha filha Alice, para quem almejo ser um pai verdadeiro. Meus amores imensos, oceânicos, para ambas 


\section{Agradecimentos}

A Eliana Yunes, orientadora da tese, pelos conselhos, incentivo, afeto e paciência.

Aos professores do Departamento de Letras, pelas críticas e colaborações.

Ao $\mathrm{CNPq}$, pelo suporte financeiro que me permitiu realizar e concluir o curso.

Aos meus colegas de curso, cujos breves contatos foram marcantes e solidários.

À minha família, por me aceitar como eu sou.

À minha mãe (1944 - 2003), pelas memórias de amor e coragem vivas em mim.

À minha companheira de alegrias e tristezas, a certeza das horas incertas.

À minha filhinha que, aos dois aninhos, aceitou que o papai tinha de trabalhar no fim de semana.

Aos amigos que de alguma forma contribuíram com seu apoio para esta tese.

Às professoras e professores da banca, pelos conselhos e lições.

Ao meu estagiário de pesquisa Rian Oliveira Rezende, pela inestimável colaboração.

Aos educadores e alunos das instituições de ensino onde as pesquisas de campo foram realizadas, pela paciência e apoio.

Aos Orixás e espíritos de luz, pela força, carinho e serenidade nas adversidades. 


\section{Resumo}

Pereira, Carlos Eduardo Klimick; Eliana Lúcia Madureira Yunes Garcia. Uma ponte pela Escrita: A narratividade do RPG como estímulo à escrita e à leitura. Rio de Janeiro, 2008. 200 p. Tese de Doutorado Departamento de Letras, Pontifícia Universidade Católica do Rio de Janeiro.

Uma ponte pela escrita é uma tese de doutoramento em Letras, na área de Literatura Brasileira, pela PUC-Rio com pesquisa realizada de 2004 a 2008, enfocando a aquisição de habilidades de leitura e escrita. Professores em diversos níveis de ensino reclamam que seus alunos lêem e escrevem cada vez menos e pior. Contudo, no altamente interativo meio da Internet cresce o volume de emails e o número de blogs, websites, fotologs etc. Portanto, parece plausível que trazer um nível mais evidente de interatividade na relação do leitor com a obra literária e os colegas poderia ser um caminho para despertar o gosto pela leitura e escrita nos estudantes. As histórias interativas conhecidas como RPG (role playing game) teriam características mobilizadoras e facilitadoras que poderiam ser úteis para resgatar o espaço da literatura nas escolas. Esta hipótese foi testada em quatro pesquisas de campo realizadas: alunos de graduação na universidade; alunos do Ensino Médio da rede pública; alunos adolescentes do Instituto Nacional de Educação de Surdos (INES); grupos de voluntários fora do ambiente escolar. O objetivo foi estimular a leitura ao motivar uma escrita criativa a partir das narrativas vivenciadas interativamente pelos alunos e voluntários. Métodos de pesquisa incluíram observações, entrevistas, questionários e análises de dados. $\mathrm{O}$ método TNI (Técnicas para Narrativas Interativas) para utilização de histórias interativas para fins didáticos foi desenvolvido durante a pesquisa.

\section{Palavras-Chave:}

Leitura, escrita, complexidade, Barthes, narrativa, interatividade, RPG. 


\section{Abstract}

Pereira, Carlos Eduardo Klimick; Eliana Lúcia Madureira Yunes Garcia. A bridge through writting: Narrativity in RPG stimulating reading and writting. Rio de Janeiro, 2008. 200 p. Dr. Dissertation - Departamento de Letras, Pontifícia Universidade Católica do Rio de Janeiro.

A bridge through writing is a dissertation in Portuguese, in the area of Brazilian Literature, by the Catholic University of Rio with research made between 2004 and 2008, with focus on students' acquisition of reading and writing skills. Teachers in several levels of education complain that their students reading and writing skills are decaying more and more. But, in the highly interactive environment of the Internet the volume of e-mails and quantity of blogs, websites, fotologs etc, keeps growing. Therefore, it seems plausible that bringing a more evident level of interactivity to the relation between the reader and the literary work and the classmates could be a way to awaken the taste for reading and writing in the students. The interactive stories known as RPG (role playing game) would have mobilizing and facilitating characteristics that could be useful to retrieve literature's space at schools. This hypothesis was tested in four field researches: undergraduate students at an university; high school students of a public school; teen-age students of the National Institute for Education of Deaf People (INES); groups of volunteers outside the school environment. The objective was to stimulate reading by motivating a creative writing based upon the narratives experienced by the students and volunteers. Research methods included observations, interviews, questionnaires and data analysis. The method TNI (Techniques for Interactive Narratives) for the application of interactive stories for educational purposes was developed during the research.

\section{Keywords}

Reading, writing, complexity, Barthes, narrative, interactivity, RPG. 


\section{Sumário}

1. Introdução 9

1.1. Horizonte teórico. 11

1.2. Práxis. 24

2. Role Playing Game (RPG) 27

2.1. Uma história para o RPG. 28

2.2. Características e componentes 34

2.3. Uma proposta de poética para o RPG 44

2.4. Questões do RPG: críticas e considerações. 53

3. Práxis Lítero-Educacional 77

3.1. Epistemologia da Complexidade e o caminho pela literatura. 78

3.2. RPG e Educação 88

3.3. TNI - Técnicas para Narrativas Interativas 101

3.4. A leitura estimulada pelo RPG - crítica e ponderações 108

$\begin{array}{ll}\text { 4. Pesquisa de Campo } & 119\end{array}$

$\begin{array}{ll}\text { 4.1. Metodologia } & 120\end{array}$

4.2. PUC-Rio: RPG para escritores 126

4.3. Colégio Estadual Vicente Januzzi: Capitães da Areia 132

4.4. INES - Instituto Nacional de Educação de Surdos 153

4.5. Estudo com voluntários fora do ambiente escolar 157

5. Conclusão 164

$\begin{array}{ll}\text { 6. Referências Bibliográficas } & 176\end{array}$

7. Anexos 